\title{
Readiness for pronunciation during the reading process
}

\author{
JOËL PYNTE \\ Laboratoire de Psychologie Expérimentale, Université de Provence, Aix-en-Provence 13100, France
}

\begin{abstract}
The task proposed to the $\mathrm{S}$ consisted of reading a series of three numbers projected on a screen. Depending on the series presented, the number projected at the center (test) required one or more syllables to be pronounced. The results show that the more syllables it takes to pronounce it, the longer the eye fixation on that number lasts. This suggests that a mechanism of readiness for pronunciation co-occurs with visual processing.
\end{abstract}

Any complex perceptual activity is achieved through at least two stages (or on two simultaneous levels): (1) pick-up of information (achieved along a series of elementary perceptual acts); and (2) integration of this information (which finally allows the construction of a perceptual representation). For instance, in the manual exploration of an object, the series of tactile stimulations is "translated into a single impression of form [Gibson, 1962]."

Reading is a perceptual activity of a somewhat particular kind. The first level of treatment is indeed observable: the pick-up of visual information is achieved through a series of eye fixations, each of which is on the order of $0.2-0.3 \mathrm{sec}$ long (cf. Woodworth, 1945). On the other hand, the second level, i.e., the perceptual level, is not observable.

While we do construct a visual image along each eye fixation, it seems that we never integrate these isolated fragments so as to construct the wholistic visual image of a sentence or even of a phrase.

In the course of reading, various more or less abstract types of treatment are substituted for perceptual integration: morphemic, syntactic, semantic. How can these be achieved without the support of a perceptual representation? How do we proceed to keep up the perceptual information (collected in the course of several elementary visual acts) in an unorganized, unintegrated state all the time it takes to read a meaningful unit?

We may, for instance, pronounce the reading material and so deal with a sound sequence rather than with a series of visual images. As a matter of fact, the elementary auditory act lasts longer than the elementary visual act, and we are able to apprehend at one time the auditory information needed for the processing of a whole sentence.

According to Fraisse (1957), all the sounds (whether they are or are not produced by the S) which occur in the course of a temporal period (called "psychological present") lasting a few seconds (i.e., the duration of a short sentence) are auditorially subitized and thus appear to be occurring simultaneously. He writes: "In this present there is an ordering, periods between the constructive elements, but there is a kind of simultaneity as well, which is due to the very unity of my perceptual act [p. 84]."

Most of the time, however, there is no explicit pronunciation during the reading process. In all cases, though, there may be a preparatory stage of the pronunciation process implying programming (but no achievement) of an articulatory sequence.

We may, therefore, assume that pronunciation is being achieved through two different stages (one and only one of which occurs during silent reading): programming on the one hand, and performance on the other hand, with programming taking place first.

The study of actual pronunciation during the reading process shows that pronunciation is always behind the pick-up of visual information (cf. Buswell, 1920, quoted in Woodworth, 1945). Is this overlap-the so-called oculomotor latency-merely ascribable to the effectors' inertia?

Eriksen, Pollack, and Montague (1970) instructed their Ss to read just one word (or number). They have shown that verbal reaction time is a function of the number of syllables required to pronounce the stimulus material.

This gives clear indication that actual pronunciation requires a preparation period. It does not demonstrate, however, that the preparation period is a component of the oculomotor latency. As a matter of fact, as measured by Eriksen et al, reaction time started at the onset of presentation. Besides, the duration of exposure was identical for all the stimuli. There is the possibility that, during reading, the readiness for pronunciation is performed, while the eyes of the $S$ are still fixated on the concerned part of the reading material.

In order to determine whether the readiness for pronunciation occurs during or after eye fixation, the following should be measured: (1) duration of eye fixation, and (2) reaction time, starting from the completion of eye fixation.

If, as we assumed, readiness for pronunciation is effected even in the absence of actual pronunciation, it probably occurs in the course of, not after, eye fixation. Such is the assumption we decided to test. In order to do so, we measured the duration of eye fixation, using as stimuli a series of two-digit numbers which 


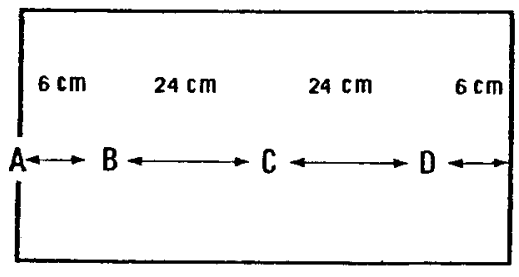

Fig. 1. Stimulus arrangement on the screen. A, fixation point; $B$, first number; $C$, second number (test); $D$, third number.

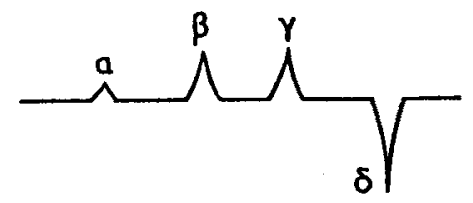

Fig. 2. Typical graph: $\alpha$, eye movement from $\mathbf{A}$ to $\mathbf{B} ; \beta$, eye movement from $B$ to $C ; \gamma$, eye movement from $C$ to $D ; \delta$, eye movement from $D$ to $A$ or $B$ or $C$.

required one or more syllables to be pronounced.

\section{METHOD}

The procedure used consists of recording eye movements that occur during the reading of sequences constituted by three separate numbers.

\section{Experimental Device}

The $S$ is seated $60 \mathrm{~cm}$ from a translucent screen, $60 \mathrm{~cm}$ wide. His head is held in position by a chinrest. A slide projector placed behind the screen is operated by a pulse generator which permits adjustment of the duration of exposure. A photoelectric cell connected to a second pulse generator allows one to register precisely, on one of the tracks of a writing recorder, the time interval during which the screen is lighted. Skin electrodes are placed at the temples of the $S$. The potential differences obtained are amplified and recorded on a second track of the writing recorder.

\section{Task}

Prior to presentation of the stimulus, the $S$ is instructed to fixate a dot located on the left rim of the screen. When a stimulus appears, he has to read it as quickly as possible without pronouncing it. He is allowed 2 sec to achieve this. After these $2 \mathrm{sec}$, the stimulus disappears and he has to report orally the numbers he has seen. Another stimulus is then presented with the same procedure.

\section{Stimulus}

Two different stimuli were prepared. Each stimulus consists of a series of three two-digit numbers. The arrangement of the numbers is shown in Fig. 1. The first number in the series is situated $6 \mathrm{~cm}$ from the left rim of the screen (a fixation point is stuck on this rim), and the numbers are separated by intervals $24 \mathrm{~cm}$ long. The third number appears $6 \mathrm{~cm}$ inside the right rim of the screen. Each of the two-digit numbers is $0.9 \mathrm{~cm}$ in length. The visual angle subtended by the whole sequence (fixation point included) is approximately $45 \mathrm{deg}$.

Of the three numbers constituting a stimulus, the only number in which we are interested is the second number (the one appearing in the center of the screen). The test number is "90" in Stimulus 1 and "30" in Stimulus 2.

\section{Independent Variable}

The independent variable selected is the number of syllables needed to pronounce the test number. There are two different lengths: four syllables are needed for Stimulus 1 (quatre-vingt-dix) and just one for Stimulus 2 (trente).

\section{Subjects}

Twenty-four students in psychology served as Ss in the experiment. They all were native speakers of French.

\section{Experimental Design}

Each $S$ is presented both stimuli. Half the Ss are presented Stimulus 1 first and then Stimulus 2; for the other half, the presentation is in the reverse order.

\section{Dependent Variable}

The electro-oculographic records obtained during reading of the stimuli are all of the shape shown in Fig. 2. (Note that the shape of the record corresponds to a recording excluding the continuous components.) The dependent variable is the distance $\beta \leftrightarrow \gamma$, which indicates the duration of eye fixation on the test number.

\section{RESULTS AND DISCUSSION}

The data consist of 21 measure pairs (three questionable records have been eliminated). The two means obtained are shown in Table 1 (both in millimeters and in seconds). Eye-fixation time on number " 90 " is longer than eye-fixation time on number "30." The difference is significant $(p<.001, t$ test $)$. However, the observed difference may be due to a difference in the design of the digits which compose the test numbers ("9" may require longer to be recognized than "3"). In order to brush aside this objection, an additional experiment was carried out, with the same Ss. Experiment II was identical to Experiment I, but for the second number in the series [test number: either " 82 " (quatre-vingt-deux) or "28" (vingt-huit)]. It should be noted that, in this case, the individual digits to be perceived are identical in Stimulus 1 and Stimulus 2 test numbers. On the other hand, four syllables are necessary to pronounce the test number in Stimulus 1, while in Stimulus 2, only two syllables are necessary. The results given in Table 2 are in the same direction as the Experiment I results $(\mathrm{p}<.01)$.

Thus, the duration of eye fixation on an item depends on the number of syllables necessary to pronounce this item. The important fact, here, is that the eye-fixation time investigated was measured as the $\mathrm{S}$ was reading a sequence constituted by several items. We can, therefore, state that this eye fixation is part of an integrated ocular

Table 1

Eye Fixation Means: Experiment I

\begin{tabular}{llll}
\hline \multicolumn{2}{c}{90} & \multicolumn{2}{c}{30} \\
\hline $7.95 \mathrm{~mm}$ & $0.52 \mathrm{sec}$ & $6.11 \mathrm{~mm}$ & $0.41 \mathrm{sec}$ \\
\hline
\end{tabular}

Table 2

Eye Fixation Means: Experiment II

\begin{tabular}{llll}
\hline \multicolumn{2}{c}{82} & \multicolumn{2}{c}{28} \\
\hline $8.66 \mathrm{~mm}$ & $0.58 \mathrm{sec}$ & $7.28 \mathrm{~mm}$ & $0.49 \mathrm{sec}$ \\
\hline
\end{tabular}


search behavior occurring whenever we have to read a rather long verbal stimulus.

During the reading process, readiness for pronunciation thus seems to occur while the eye of the $S$ still fixates the concerned part of the stimulus. Actual pronunciation occurs later (in its turn, along the articulatory sequence).

Does the preparatory stage occur even in the case of silent reading? Some recent data seem to argue against this assumption: Klapp (1971) has shown that, in the case of word recognition not ending in an explicit pronunciation (e.g., when the task of the $S$ is to compare this word to another), implicit pronunciation does not always occur. It occurs only for the "different" response. "Same" response can be produced through a purely visual processing.

Also, Klapp, Anderson, and Bérrian (1973) have shown that when the $\mathrm{S}$ has to say whether or not a word matches a picture there is no implicit pronunciation.

As a matter of fact, the experimental situations used by Klapp et al differ appreciably from reading. The results obtained by these authors seem to demonstrate that implicit pronunciation feedback is not essential to visual recognition (which indeed is the conclusion they draw from their experiment). They do not demonstrate that the S can do without the support of implicit pronunciation in the semantic and syntactic integration of a text.

In an additional study, we plan to replicate the experiment presented here. No vocalization will be required from Ss. The task will consist of either a mere silent reading or the search for certain relations between the series items.

\section{REFERENCES}

Eriksen, C., Pollack, M., \& Montague, W. Implicit speech: Mechanism in perceptual encoding? Journal of Expeximental Psychology, 1970, 84, 502-507.

Fraisse, P. Psychologie du temps. Paris: Presses Universitaires de France, 1957.

Gibson, J. J, Observations on active touch. Psychological Review, 1962, 69, 477-491.

Klapp, S. Implicit speech inferred from response latencies in same-different decisions. Journal of Experimental Psychology, $1971,91,262-267$.

Klapp, S., Anderson, W., \& Bérrian, R. Implicit speech in reading, reconsidered. Journal of Experimental Psychology, 1973, 100, 368-374.

Woodworth, R. S. Experimental psychology. New York: Holt, 1945 .

(Received for publication January 21, 1974; revision received March 1,1974 .) 